\section{A new partial diallel model adapted to analyze reciprocal effects in grain yield of maize}

\author{
Nazaré Mateus Barata ${ }^{1}$, Carlos Alberto Scapim ${ }^{2}$, Terezinha \\ Aparecida Guedes ${ }^{1}$, Vanderly Janeiro ${ }^{1}$, Ronald José Barth \\ Pinto $^{2}$, Rodrigo Ivan Contreras Soto ${ }^{3}$ and Maurício Carlos Kuki ${ }^{*}$
}

\begin{abstract}
Comparison between two distinct groups using a partial diallel and considering reciprocal effects has not been described in the scientific literature, limiting diallel analysis results. This study compared two groups of parents using a partial diallel, and analyzed the general and specific combining ability and reciprocal effects, divided into maternal and cytoplasmic. A partial diallel was established with nine maize hybrids, including the $F_{1}$ and reciprocal hybrids for grain yield. For this application, the reciprocal effects were not significant. The proposed model would provide plant breeders with additional information to analyze partial diallel mating designs.
\end{abstract}

Keywords: Combining ability, cytoplasmic effects maternal effects.

\section{INTRODUCTION}

Maize breeding programs increase the efficiency in planning crosses by evaluating the combining ability of genitors in diallel mating schemes. Usually, breeders design crosses among inbred lines or varieties that result in $F_{1}$ hybrids, which may include the reciprocal $F_{1}$ 's and their parents, resulting in a very large number of crosses. To control this problem, the partial diallel of parents from contrasting populations was proposed (Miranda Filho and Geraldi 1984, Geraldi and Miranda Filho 1988, Ferreira et al. 2008).

Diallel mating designs are mainly used to assess the general and specific combining abilities (GCA and SCA, respectively) (Griffing 1956), to partition the heterosis in different effects (Gardner and Eberhart 1966) and to study the genetic control of quantitative traits (Hayman 1954a, 1954b). However, the reciprocal effects (REC), which can be partitioned into maternal (MAT) and cytoplasmic or extrachromosomal effects (CIT), are also a study target.

The available models compare two groups of different parents evaluating the GCA and SCA effects (with heterosis evaluation); or evaluate the per se analysis of the parents but without considering reciprocal effects (Geraldi and Miranda Filho 1988, Griffing 1956), or evaluate the combining ability and reciprocal effects, which are partitioned into maternal and cytoplasmic effects. More specifically, the reciprocal crosses are included in Griffing's Method 1 and Method 3, by which the reciprocal effects as well as non-maternal effects (Zhang and Kang 1997, Zhang et al. 2005) can be calculated. However, to date, a comparison of two distinct heterotic groups in a partial diallel scheme and considering reciprocal effects has not been described, which limits diallel analysis
Crop Breeding and Applied Biotechnology 19: 22-30, 2019 Brazilian Society of Plant Breeding. Printed in Brazil http://dx.doi.org/10.1590/198470332019v19n1a04

\section{*Corresponding author: E-mail: mcarloskuki@gmail.com (D) ORCID: 0000-0002-6401-2313}

Received: 04 April 2018 Accepted: 02 November 2018

${ }^{1}$ Universidade Estadual de Maringá, Departamento de Estatística, 87.020-900, Maringá, PR, Brazil

${ }^{2}$ Universidade Estadual de Maringá, Departamento de Agronomia, 87.020-900, Maringá, PR, Brazil

${ }^{3}$ Universidad de O'Higgins, Instituto de Ciencias Agronómicas, Rancagua, Sexta Región, 28.20000, Chile 
and the reciprocal effect over the most important traits in maize.

In maize, for instance, reciprocal effects have been demonstrated for quantitative traits such as grain dry-down (Magari et al. 1996) and resistance to kernel disease caused by Aspergillus flavus (Zhang et al. 1997). According to Fan et al. (2014), for several reasons, plant breeders may not always be able to include reciprocal crosses in experiments. Reciprocal crosses may fail or produce an insufficient seed quantity. In crops such as maize, where grain yield (GY) is largely determined by endosperm, reciprocal crosses are important and knowledge about the impact of the inclusion or non-inclusion of reciprocal $F_{1}$ crosses in a diallel analysis on GY is essential. The results obtained by Fan et al. (2014) show that the inclusion of reciprocal crosses in a diallel greatly influences GY and the estimation of GCA and SCA effects.

The aims of this study were to: a) a comparison of a single model with fixed and then random effects, of two groups of parents in a partial diallel, as proposed by Geraldi and Miranda Filho (1988), and b) the analysis of the GCA, SCA and reciprocal effects and divided into maternal and cytoplasmic effects, as proposed by Cockerham and Weir (1977) on grain yield.

\section{MATERIAL AND METHODS}

The proposed model was applied in a dataset obtained from a partial diallel cross scheme. The experiment was carried out with nine maize hybrids on a field of the experimental station of Iguatemi (lat 23ㅇ 25' S, long 51은 $57^{\prime}$ W, alt $510 \mathrm{~m}$ asl), of the State University of Maringá, Paraná, Brazil. The genotypes were divided in two groups; group 1 comprised the cultivars: 8330, CD3121-1, AG8080, Flash, and Dekalb 350 (denoted as 1,2,3,4, and 5), and group 2 the cultivars 30F80, Strike, Speed, and CD3121-2 (denoted as 6, 7, 8, and 9). The hybrids were obtained from a partial diallel scheme (two contrasting groups), resulting in $20 \mathrm{~F}_{1}$ double hybrids and $20 \mathrm{~F}_{1}$ reciprocal hybrids.

The 49 treatments that include 40 hybrids and 9 parents were evaluated in the growing season 2007/2008 (Table 1). The experiment was arranged in a complete block design with three replications. Each plot consisted of one 5-m row, spaced at 0.9 meters between rows and with plants spaced $0.2 \mathrm{~m}$ apart. Grain yield (GY; kg ha-1) was measured a ter

Table 1. The 49 maize treatments, including 40 hybrids and 9 parents evaluated in the growing season 2007/2008

\begin{tabular}{|c|c|c|}
\hline \multirow{2}{*}{$\begin{array}{l}\text { Parents } \\
18330\end{array}$} & \multicolumn{2}{|c|}{ Hybrids $F_{1}$ 's and reciprocals } \\
\hline & $1 \times 6(8330 \times 30 F 80)$ & $9 \times 3$ (CD3121-2 x AG8080) \\
\hline 2 CD3121-1 & $6 \times 1(30 F 80 \times 8330)$ & $4 \times 6$ (Flash x 30F80) \\
\hline 3 AG8080 & $1 \times 7$ (8330 x Strike) & $6 \times 4$ (30F80 x Flash) \\
\hline 4 Flash & $7 \times 1$ (Strike x 8330) & $4 \times 7$ (Flash $\times$ Strike) \\
\hline 5 Dekalb 350 & $1 \times 8$ (8330 x Speed) & $7 \times 4$ (Strike x Flash) \\
\hline $630 F 80$ & $8 \times 1$ (Speed x 8330) & $4 \times 8$ (Flash $\times$ Speed) \\
\hline \multirow[t]{12}{*}{9 CD3121-2 } & $2 \times 6$ (CD3121-1 x 30F80) & 9 x 4 (CD3121-2 x Flash) \\
\hline & $6 \times 2(30 F 80$ x CD3121-1) & $5 \times 6$ (Dekalb 350 x 30F80) \\
\hline & $2 \times 7$ (CD3121-1 x Strike) & $6 \times 5$ (30F80 x Dekalb 350) \\
\hline & 7 × 2 (Strike x CD3121-1) & $5 \times 7$ (Dekalb 350 × Strike) \\
\hline & $2 \times 8$ (CD3121-1 x Speed) & $7 \times 5$ (Strike x Dekalb 350) \\
\hline & $3 \times 6($ AG8080 x 30F80) & $9 \times 5$ (CD3121-2 x Dekalb 350) \\
\hline & $6 \times 3$ (30F80 x AG8080) & \\
\hline & 3 x 7 (AG8080 x Strike) & \\
\hline & 7 × 3 (Strike x AG8080) & \\
\hline & $3 \times 8$ (AG8080 x Speed) & \\
\hline & 8 x 3 (Speed x AG8080) & \\
\hline & $3 \times 9$ (AG8080 x CD3121-2) & \\
\hline
\end{tabular}




\section{NM Barata et al.}

correction to $13 \%$ moisture. Fertilizer and field management practices recommended for optimum maize production were used at each location (EMBRAPA 2006).

A partial diallel scheme, composed by the parents, $F_{1}$ and reciprocal $F_{1}$ crosses, was evaluated by the following statistical model:

$y_{i j k}=\mu+b_{k}+G_{j}+e_{i j k}$

where: $Y_{\mathrm{ijk}}$ corresponds to the response variable (grain yield) obtained in the trial; $\mu$ is the general mean; $\mathrm{G}_{\mathrm{ij}}$ the ij diallel effect; $b_{k}$ the $k^{\text {th }}$ block effect $k=1 \ldots u$ ( $u$ the number of blocks), and $e_{i j k}$ the random error effect with distribution NID (0, $\left.\sigma^{2}\right)$. The genetic effects were included in a diallel sub-model, as follows:

$G_{i j}=0.5\left(g r_{1}+g r_{2}\right)+g_{i}+g_{j}+s_{i j}+d_{i}-$

with the restrictions:

$s_{i j}=s_{j i}, r_{i j}=r_{i j i}$

Where Gij is the diallel effect; $g_{1}$ and $g_{2}$ are the contrasting means between groups 1 and $2 ; g_{i}$ is the GCA effect of the $i^{\text {th }}$ parent of group 1 with $i=1, \ldots, p ; g$ the GCA effect of the $j^{\text {th }}$ parent in group 2 with $j=6, \ldots, q ; p$ and $q$ are the number of parents in group 1 and 2, respectively; $s_{i j}$ is the SCA effect between parent $i$ and $j$, which represent group 1 and 2, respectively; $d_{i}$ and $d_{j}$ are the maternal effects of the $i^{\text {th }}$ and $j^{\text {th }}$ parent in group 1 and 2 , respectively; $r_{i j}$ is the cytoplasmic effect between the parents $i$ and $j ; d_{i}-d_{j}+r_{i j}$ represent the reciprocal variability in the diallel.

In matrix form, it was assumed that $Y$, or vector of the response variable have normal distribution $N\left(X \beta, I \sigma^{2}\right)$ for the model with fixed effects and normal distribution $\mathrm{N}(J \mu, \Sigma)$ for model with random effects; where: $\mathrm{X}$ is the incidence matrix of fixed effects, $\beta$ is the vector associated with the fixed effects, I is an identity matrix, $J$ is a vector of $1 \mathrm{~s}$, and $\Sigma$ is the matrix of variance-covariance associated with the data.

Considering the model with random effects, $g$ and $d$ have normal distribution $N\left(0, \Sigma_{\text {gd }}\right)$ for $i$ and $j$ individually, $s$ and $r$ have normal distribution with $\mathrm{N}\left(0, \sigma^{2}\right)$, and $\Sigma$ is the matrix of variance-covariance associated with the data. In the fixed model, the genetic effects were estimated by the least square method, and in the random model, the genetic effects were not estimated, since the focus is on variance components.

The system $\boldsymbol{X}^{\prime} \boldsymbol{X} \boldsymbol{B}=\boldsymbol{X}^{\prime} \boldsymbol{y}$ provides the normal equation, which with the appropriate restrictions, allows the establishment of the unique solutions:

$\sum_{k=1}^{u} \hat{b}_{k}=0 \quad ;(1+q) \hat{g} r_{1}+q(1+p) \hat{g} r_{2}=0 \sum_{i=1}^{p} \hat{g}_{i}=0 \quad ; \sum_{j=1}^{q} \hat{g}_{j}=0 \quad \hat{s}_{\bar{i}}+\sum_{j=1}^{q} \hat{s}_{j}=0 \quad \hat{s}_{j}+\sum_{i=1}^{p} \hat{s}_{j}=0 \quad ; \quad \sum_{i=1}^{p} \hat{d}_{i}+\sum_{j=1}^{q} \hat{d}_{j}=0$

The solution of the normal equations provides the estimation of the parameters that represent the effects contemplated in the proposed fixed model:

$$
\begin{aligned}
& \left.\hat{\mu}=\frac{\mathrm{Y}_{\mathrm{T}}}{\mathrm{N}} \quad ; \quad \hat{g} r_{1}=\frac{1}{\mathrm{up}(p+\mathrm{q}+\mathcal{Z}}\left[\mathrm{Y}_{(1)}-\mathrm{Y}_{(2)}-\mathrm{u}(\mathrm{p}-\not) \hat{\mu}\right] \quad ; \quad \hat{g} r_{2}=\frac{1}{\mathrm{uq}(p+\mathrm{q}+\mathcal{Z}} \mathrm{Y}_{(2)}-\mathrm{Y}_{(1)}+\mathrm{u}(\mathrm{p}-\not) \hat{\mu}\right] \\
& \hat{g}_{\mathrm{i}}=\frac{1}{\mathrm{u}(4+2 \mathrm{q})}\left[2 \mathrm{Y}_{\mathrm{i}}+\mathrm{Y}_{\mathrm{i}}+\mathrm{Y}_{\mathrm{i}}-\frac{1}{\mathrm{q}}\left(2 \mathrm{Y}_{(1)}+\mathrm{Y}_{\mathrm{H}}+\mathrm{Y}_{\mathrm{R}}\right] \quad ; \quad \hat{g}_{\mathrm{j}}=\frac{1}{\mathrm{u}(4+2 \mathrm{p})}\left[2 \mathrm{Y}_{\mathrm{j}}+\mathrm{Y}_{\mathrm{j}}+\mathrm{Y}_{\mathrm{j}}-\frac{1}{\mathrm{q}}\left(2 \mathrm{Y}_{(2)}+\mathrm{Y}_{\mathrm{H}}+\mathrm{Y}_{\mathrm{R}}\right]\right.\right. \\
& \left.\hat{s}_{i \mathrm{i}}=\frac{\mathrm{Y}_{\mathrm{i}}}{\mathrm{u}}-\hat{\mathrm{i}}+\hat{\mathrm{g}} \mathrm{r}_{1}+2 \hat{\mathrm{g}}_{\mathrm{i}} \quad \hat{\mathrm{s}}_{\mathrm{j}}=\frac{\mathrm{Y}_{\mathrm{j}}}{\mathrm{u}}-\hat{\mathrm{i}}+\hat{\mathrm{g}} \mathrm{r}_{2}+2 \hat{\mathrm{g}}_{\mathrm{j}} \quad ; \quad \hat{\mathrm{s}}_{\mathrm{ij}}=\frac{\mathrm{Y}_{\mathrm{ij}}+\mathrm{Y}_{\mathrm{j}}}{\mathrm{Q}}-\hat{\imath}+\frac{1}{2} \hat{\mathrm{g}} \mathrm{r}_{1}+\frac{1}{2} \hat{\mathrm{g}} \mathrm{r}_{2}+\hat{\mathrm{g}}_{\mathrm{i}}+\hat{\mathrm{g}}_{\mathrm{j}}\right) \quad \hat{\mathrm{d}}_{\mathrm{i}}=\frac{\mathrm{Y}_{\mathrm{i}}-\mathrm{Y}_{\mathrm{i}}}{2 \mathrm{uq}} ; \\
& \hat{\mathrm{d}}_{\mathrm{j}}=\frac{\mathrm{Y}_{\mathrm{j}}-\mathrm{Y}_{\mathrm{j}}}{2 \mathrm{up}} ; \hat{\mathrm{r}}_{\mathrm{i}}=\frac{\mathrm{Y}_{\mathrm{i}}-\mathrm{Y}_{\mathrm{j}}}{\text { Q }}-\left(\hat{\mathrm{d}}_{\mathrm{i}}-\hat{\mathrm{d}}_{\mathrm{j}}\right)
\end{aligned}
$$

If the number of parents are the same in both groups, the parameters $\hat{d}_{i}, \hat{d}_{j}$ and $\hat{r}_{i j}$ are estimates of the effects proposed in the model of Geraldi and Miranda Filho (1988) and Cockerham and Weir (1977). 
The sum of squares (SS) for blocks $(\hat{b})$, groups $(\hat{g} r)$, GCA within each group $\left(G C A g r_{1}\right.$ and $\left.G C A g r_{2}\right)$, SCA, maternal effects within each group (MATgr ${ }_{1}$ and $M A T g r_{2}$ ) and cytoplasmic or extrachromosomal (CIT) effects were represented by:

$$
\begin{aligned}
& \operatorname{SS}(\hat{b})=\frac{1}{N}\left(Y_{(1) k}+Y_{(2) k}+Y_{H k}+Y_{R k}\right)^{2}-\frac{\left(Y_{T}\right)^{2}}{u N} \\
& \operatorname{SS}(\hat{g} r)=\frac{\left[2 q(1+p) Y_{(1)}-2 p(1+q) Y_{(2)}-(p-q)\left(Y_{H}+Y_{R}\right)\right]^{2}}{2 u N p q(p+q+2)}
\end{aligned}
$$

$\operatorname{SS}\left(G_{C A g r}\right)=\frac{1}{u(4+2 q)}\left[\sum_{i=1}^{p}\left(2 Y_{i i}+Y_{i .}+Y_{i}\right)^{2}-\frac{1}{q}\left(2 Y_{(1)}+Y_{H}+Y_{R}\right)^{2}\right] \operatorname{SS}\left(\operatorname{GCAgr}_{2}\right)=\frac{1}{u(4+2 p)}\left[\sum_{j=1}^{q}\left(2 Y_{j j}+Y_{j}+Y_{j}\right)^{2}-\frac{1}{p}\left(2 Y_{(2)}+Y_{H}+Y_{R}\right)^{2}\right]$

$\operatorname{SS}\left(\operatorname{MATgr}_{1}\right)=\sum_{i=1}^{p} \frac{\left(\mathrm{Y}_{\mathrm{i} .}-\mathrm{Y}_{\mathrm{i}}\right)^{2}}{2 \mathrm{uq}}-\mathrm{MS}(\mathrm{D}) \quad \operatorname{SS}\left(\mathrm{MATgr}_{2}\right)=\sum_{j=1}^{q} \frac{\left(\mathrm{Y}_{\mathrm{j} .}-\mathrm{Y}_{\mathrm{j}}\right)^{2}}{2 \mathrm{up}}-\mathrm{MS}(\mathrm{D})$

$\mathrm{SS}(\mathrm{SCA})=\frac{1}{\mathrm{u}} \sum_{\mathrm{i}=1}^{\mathrm{p}} \mathrm{Y}_{i i}^{2}+\frac{1}{\mathrm{u}} \sum_{\mathrm{j}=1}^{\mathrm{q}} \mathrm{Y}_{j j}^{2}+\frac{1}{2 \mathrm{u}} \sum_{\mathrm{i}=1}^{\mathrm{p}} \sum_{j=1}^{q}\left(\mathrm{Y}_{i j}^{2}+\mathrm{Y}_{j i}^{2}\right)^{2}-S S(\hat{\mu})-S S\left(g r_{\ell}\right)-\operatorname{SS}\left(G C A g r_{1}\right)-S S\left(G C A g r_{2}\right)$

$\operatorname{SS}(\mathrm{CIT})=\frac{1}{2 \mathrm{u}} \sum_{i=1}^{p} \sum_{\mathrm{j}=1}^{\mathrm{q}}\left(\mathrm{Y}_{\mathrm{ij}}-\mathrm{Y}_{\mathrm{ji}}\right)^{2}-\mathrm{SS}\left(\mathrm{MATgr}_{1}\right)-\mathrm{SS}\left(\mathrm{MATgr}_{2}\right)-\mathrm{MS}(\mathrm{D})$.

The SS(MATgr $\left.{ }_{1}\right)$ SS(MATgr ${ }_{2}$ ) and SS(CIT) are corrected by the mean square (MS) and by the mean square of the difference (MS(D)) between the sum of the $F_{1}$ 's and the sum of the reciprocal $F_{1}$ 's, as suggested by Cockerham and Weir (1977), which consider this as a noise in the estimation of the variance components of the effects $d_{i}$ and $d_{j}$, as well as for the quadratic components of the same effects. The MS(D) used as correction was estimated as follows:

$\operatorname{MS}(\mathrm{D})=\frac{1}{2 \mathrm{upq}}\left(Y_{H}-Y_{R}\right)^{2}$

The mathematical expectations for variance analysis in a model with two approaches (fixed and random) in a complete block design are shown in Table 2. The environmental variance and quadratic components for fixed effects, which represent the variability of the genotypes, were estimated as follows:

Table 2. Mathematical expectations of the mean squares of the effects described by the fixed and random diallel models

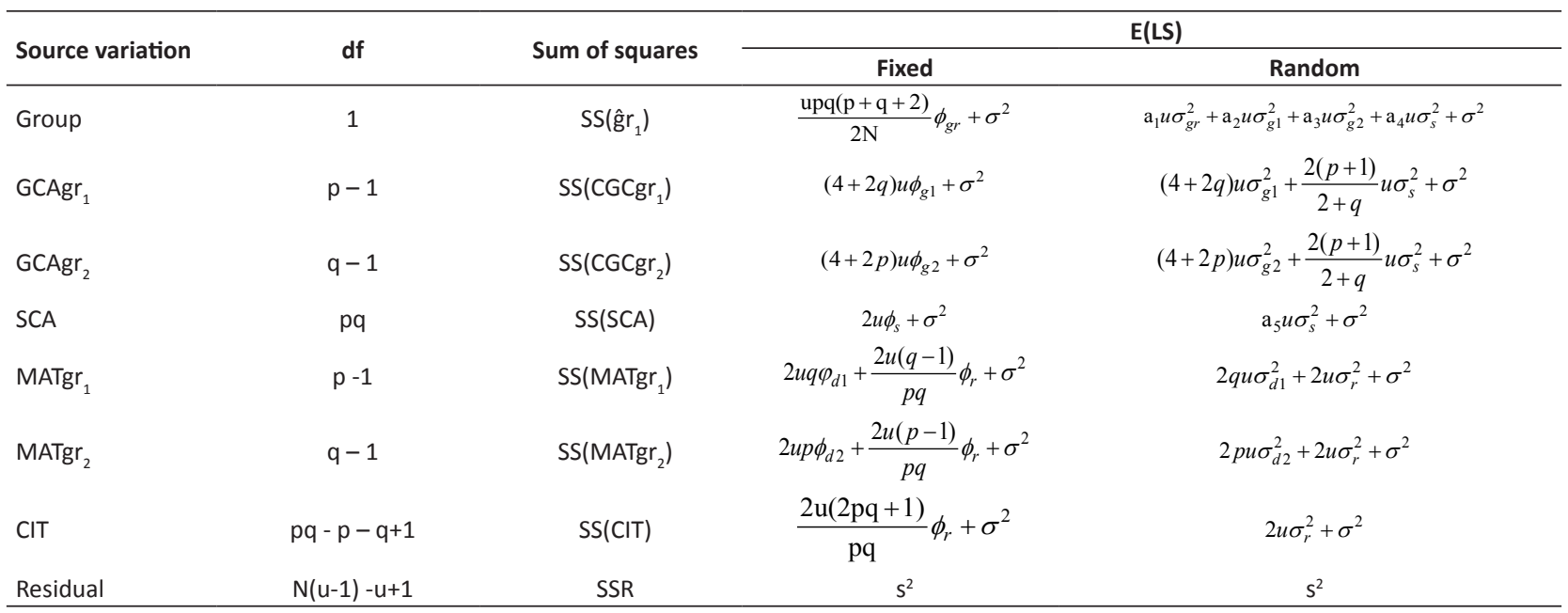

$\mathrm{N}=2 \mathrm{pq}+\mathrm{p}+\mathrm{q}$ is the number of treatments (diallel number); $\mathrm{k}=1, \ldots, u$ (being $u$ the number of blocks per treatments) and $\phi_{x}=\sum_{v} f_{v}^{2} / g l, x=g r, g 1, g 2, s, d 1, d 2$ and $r$.

$\mathrm{a}_{1}=\frac{p q(p+q+2)}{N} ; \mathrm{a}_{2}=\frac{2 q(p+q+2)}{N} ; \mathrm{a}_{3}=\frac{2 p(p+q+2)}{N} ; \mathrm{a}_{4}=\frac{2(p+q)(p+1)(q+1)}{N(p+q+2)}$ and $\mathrm{a}_{5}=\frac{2 p^{2} q+2 p q^{2}+3 p^{2}+3 q^{2}+10 p q+11 p+11 q+12}{(2+q)(2+p)(p+q+2)}$. 
$\hat{\sigma}=\operatorname{MSR} ; \quad \hat{\phi}_{\mathrm{gr}}=\frac{2 \mathrm{~N}}{\mathrm{upq}(\mathrm{p}+\mathrm{q}+2)}[\mathrm{MS}(\mathrm{GR})-\mathrm{MSR}] ; \hat{\varphi}_{\mathrm{s}}=\frac{1}{2 \mathrm{u}}[\mathrm{MS}(\mathrm{SCA})-\mathrm{MSR}] \hat{\varphi}_{\mathrm{r}}=\frac{\mathrm{pq}}{2 \mathrm{u}(\mathrm{p}-1)(\mathrm{q}-1)}[\mathrm{MS}(\mathrm{CIT})-\mathrm{MSR}]$

$\hat{\phi}_{\mathrm{g} 1}=\frac{1}{\mathrm{u}(4+2 \mathrm{q})}\left[\mathrm{MS}_{\left.\left(\mathrm{GCAgr}_{1}\right)-\mathrm{MSR}\right]}^{;} \quad \hat{\varphi}_{\mathrm{d} 1}=\frac{1}{2 \mathrm{uq}}\left[\mathrm{MS}\left(\mathrm{MATgr}_{1}\right)+\frac{\mathrm{q}-1}{\mathrm{pq}+1} \mathrm{MS}(\mathrm{CIT})-\frac{\mathrm{q}(\mathrm{p}+1)}{\mathrm{pq}+1} \mathrm{MSR}\right] ; \hat{\phi}_{\mathrm{g} 2}=\frac{1}{\mathrm{u}(4+2 \mathrm{p})}\left[{\left.\mathrm{MS}\left(\mathrm{GCAgr}_{2}\right)-\mathrm{MSR}\right]}_{;}\right.\right.$

$$
\hat{\varphi}_{\mathrm{d} 2}=\frac{1}{2 \mathrm{up}}\left[\mathrm{MS}\left(\mathrm{MATgr}_{2}\right)+\frac{\mathrm{p}-1}{\mathrm{pq}+1} \mathrm{MS}(\mathrm{CIT})-\frac{\mathrm{p}(\mathrm{q}+1)}{\mathrm{pq}+1} \mathrm{MSR}\right]
$$

These quadratic components were estimated by the method of least squares, and may therefore result in negative values; in this situation, they should be considered equal to zero. Considering the fixed and random-effect models, the hypotheses to compare the effects analyzed in this study are shown in Table 3, with their respective statistics for the F-test and degrees of freedom. For the fixed effects, the variances of genetic effects were calculated as:

$\operatorname{Var}[\hat{\mu}]=\frac{1}{N N} \sigma^{2} \quad \operatorname{Var}\left[\hat{g}_{1}\right]=\frac{2 \mathrm{q}(1+\mathrm{p})^{2}}{\mathrm{up}(\mathrm{p}+\mathrm{q}+2)^{2}} \sigma^{2} \quad \operatorname{Var}\left[\hat{g} r_{2}\right]=\frac{2 \mathrm{p}(1+\mathrm{q})^{2}}{\mathrm{uq}(\mathrm{p}+\mathrm{q}+2)^{2}} \sigma^{2} \quad \operatorname{Var}\left[\hat{g}_{i}\right]=\frac{\mathrm{p}-1}{\mathrm{up}(4+2 \mathrm{q})} \sigma^{2} \quad \operatorname{Var}\left[\hat{g}_{j}\right]=\frac{\mathrm{q}-1}{\mathrm{uq}(4+2 \mathrm{p})} \sigma^{2}$

$\operatorname{Var}\left[\hat{s}_{i i}\right]=\frac{\mathrm{q}(\mathrm{p}+\mathrm{q}+1)}{\mathrm{u}(\mathrm{p}+\mathrm{q}+2)(2+\mathrm{q})} \sigma^{2} \quad \operatorname{Var}\left[\hat{s}_{j j}\right]=\frac{\mathrm{p}(\mathrm{p}+\mathrm{q}+1)}{\mathrm{u}(\mathrm{p}+\mathrm{q}+2)(2+\mathrm{p})} \sigma^{2} \quad \operatorname{Var}\left[\hat{\mathrm{s}}_{\mathrm{ij}}\right]=\frac{4 \mathrm{pq}+\mathrm{p}^{2} \mathrm{q}+3 \mathrm{p}+\mathrm{p}^{2}+\mathrm{q}^{2}+\mathrm{pq}^{2}+3 \mathrm{q}+4}{2 \mathrm{u}(\mathrm{p}+\mathrm{q}+2)(\mathrm{q}+2)(\mathrm{p}+2)} \sigma^{2} \quad \operatorname{Var}\left[\hat{d}_{i}\right]=\frac{1}{2 \mathrm{uq}} \sigma^{2}$;

$\operatorname{Var}\left[\hat{d}_{j}\right]=\frac{1}{2 \mathrm{up}} \sigma^{2} \quad \operatorname{Var}\left[\hat{r}_{j}\right]=\frac{\mathrm{N}}{2 \mathrm{upq}} \sigma^{2} \quad \operatorname{Var}\left[\hat{g} r_{1}-\hat{g} r_{2}\right]=\frac{2 \mathrm{~N}}{\mathrm{upq}(\mathrm{p}+\mathrm{q}+2)} \sigma^{2}$.

For $i \neq k$ with $i=1,2, \ldots, k-1, k+1, \ldots, p$ and for $j \neq k^{\prime}$ with $j=1,2, \ldots, k^{\prime}-1, k^{\prime}+1, \ldots, q$. The variances for the effects of differences were estimated as follows:

$$
\begin{aligned}
& \operatorname{Var}\left[\hat{g}_{i}-\hat{g}_{k}\right]=\frac{1}{\mathrm{u}(2+\mathrm{q})} \sigma^{2} ; \quad \operatorname{Var}\left[\hat{g}_{j}-\hat{g}_{k^{\prime}}\right]=\frac{1}{\mathrm{u}(2+\mathrm{p})} \sigma^{2} ; \operatorname{Var}\left[\hat{s}_{j j}-\hat{s}_{k^{\prime} k^{\prime}}\right]=\frac{2 \mathrm{p}}{\mathrm{u}(2+\mathrm{p})} \sigma^{2} ; \\
& \left.\operatorname{Var}\left[\hat{s}_{i j}-\hat{s}_{i k^{\prime}}\right]=\frac{\mathrm{p}+1}{\mathrm{u}(2+\mathrm{p})} \sigma^{2} ; \quad \operatorname{Var}\left[\hat{s}_{i j}-\hat{s}_{k j}\right]=\frac{\mathrm{q}+1}{\mathrm{u}(2+\mathrm{q})} \sigma^{2}\right]=\frac{\mathrm{pq}+\mathrm{p}+\mathrm{q}+2}{\mathrm{u}(2+\mathrm{q})(2+\mathrm{p})} \sigma^{2} ; \operatorname{Var}\left[\hat{d}_{i}-\hat{d}_{k}\right]=\frac{1}{\mathrm{q}} \sigma^{2} \quad \operatorname{Var}\left[\hat{d}_{j}-\hat{d}_{k^{\prime}}\right]=\frac{1}{\mathrm{up}} \sigma^{2} \\
& \operatorname{Var}\left[\hat{r}_{i j}-\hat{r}_{k j}\right]=\frac{\mathrm{q}+1}{\mathrm{uq}} \sigma^{2} ;
\end{aligned}
$$

Before calculating the mean square expectations, the variance components of genetic effects were estimated as follows:

$$
\begin{aligned}
& \hat{\sigma}_{g r}^{2}=\frac{N}{u p q(p+q+2)}\left[M S(G R)-\frac{q(p+q+2)}{N(2+q)} M S\left(G C A_{g r 1}\right)-\frac{q(p+q+2)}{N(2+q)} M S\left(G C A_{g r 2}\right)-\right. \\
& -\frac{2 p q\left(3 p^{3} q+3 p q^{3}+3 p^{3}+3 q^{3}+6 p^{2} q^{2}+p^{2} q^{3}+p^{3} q^{2}+4 q+4 p+8 p q+8 p^{2}+8 q^{2}+10 p^{2} q+10 p q^{2}\right)}{N(2+q)(2+p)\left(2 p^{2} q+2 p q^{2}+3 p^{2}+3 q^{2}+10 p q+11 p+11 q+12\right)} M S(S C A)- \\
& \left.-\frac{p q\left(2 p^{3} q^{2}+2 p^{2} q^{3}+3 q^{3}+3 p^{3}+20 p^{2} q^{2}+49 p q^{2}+49 p^{2} q+29 p^{2}+29 q^{2}+114 p q+6 p^{3} q+6 q^{3} p+72 p+72 q+48\right)}{N(2+q)(2+p)\left(2 p^{2} q+2 p q^{2}+3 p^{2}+3 q^{2}+10 p q+11 p+11 q+12\right)} M S R\right] \\
& \hat{\sigma}_{g 1}^{2}=\frac{1}{2 u(2+q)}\left[M S\left(G C A_{g r 1}\right)-\frac{2(q+1)(2+p)(p+q+2)}{2 p^{2} q+2 p q^{2}+3 p^{2}+3 q^{2}+10 p q+11 p+11 q+12} M S(S C A)-\right. \\
& \left.-\frac{p^{2}-q+3 p+4-q^{2}}{2 p^{2} q+2 p q^{2}+3 p^{2}+3 q^{2}+10 p q+11 p+11 q+12} M S R\right] \\
& \hat{\sigma}_{g 2}^{2}=\frac{1}{2 u(2+p)}\left[M S\left(G C A_{g r 2}\right)-\frac{2(p+1)(2+q)(p+q+2)}{2 p^{2} q+2 p q^{2}+3 p^{2}+3 q^{2}+10 p q+11 p+11 q+12} M S(S C A)-\right. \\
& \left.-\frac{-p^{2}-p+3 q+4+q^{2}}{2 p^{2} q+2 p q^{2}+3 p^{2}+3 q^{2}+10 p q+11 p+11 q+12} M S R\right]
\end{aligned}
$$


Table 3. Hypotheses, statistics for F-test and degrees of freedom for the parameters of fixed and random models

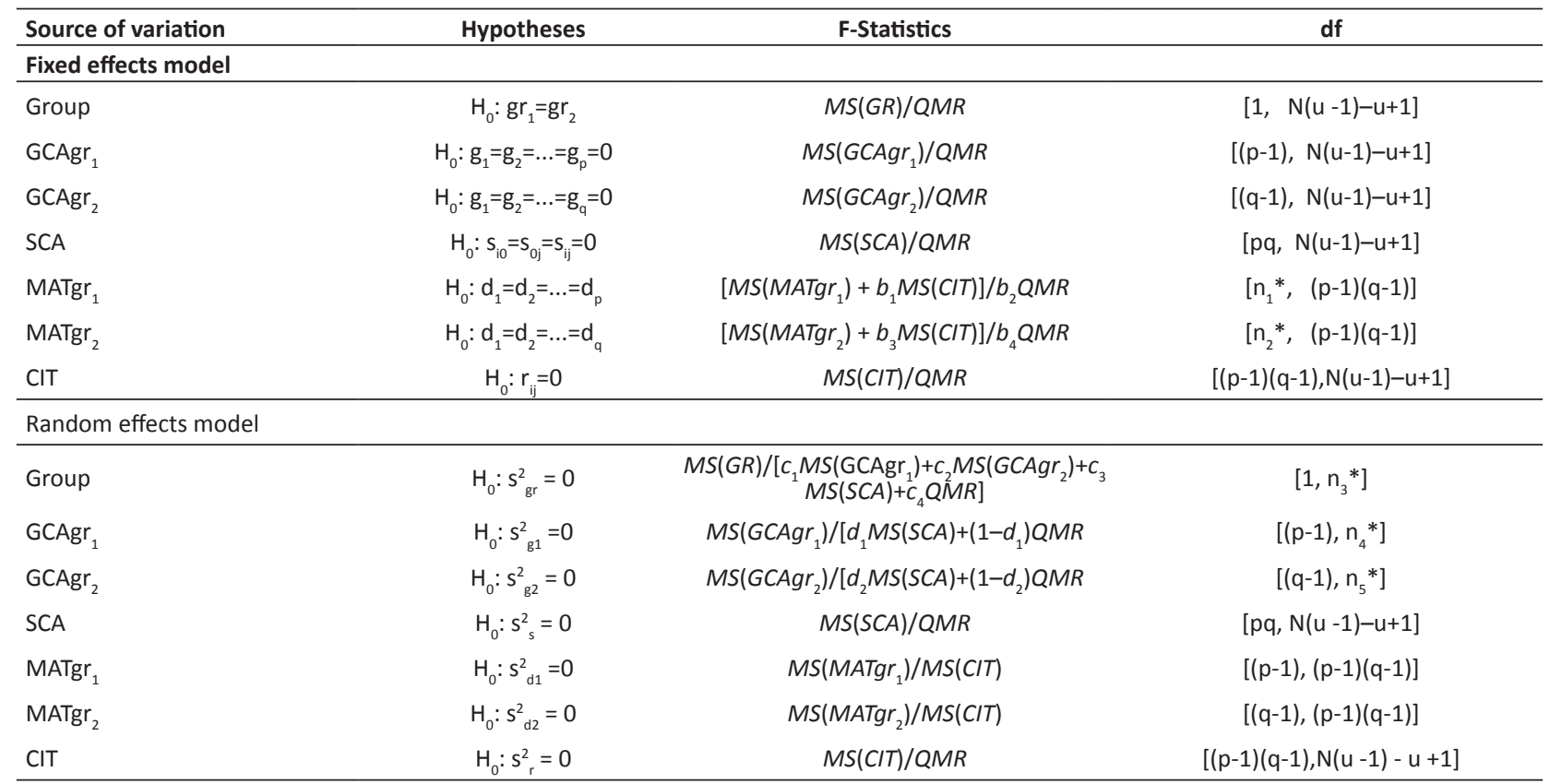

* The df of linear combinations of least squares associated to F-test was calculated using the Satterthwaite (1946) approximation, as suggested by Gaylor and Hopper (1969), and Sahai and Ojeda (2004).

The degrees of freedom (v1, v2, v3 and v4) were calculated as:

$v_{1}=\frac{\left[M S\left(M A T g r_{1}\right)+b_{1} M S(C I T)\right]^{2}}{\frac{\left[M S\left(M A T g r_{1}\right)\right]^{2}}{p-1}+\frac{\left[b_{1} M S(C I T)\right]^{2}}{(p-1)(q-1)}} \quad v_{2}=\frac{\left[M S\left(M A T g r_{2}\right)+b_{3} M S(C I T)\right]^{2}}{\frac{\left[M S\left(M A T g r_{1}\right)\right]^{2}}{q-1}+\frac{\left[b_{3} M S(C I T)\right]^{2}}{(p-1)(q-1)}} \quad v_{3}=\frac{\left[c_{1} M S\left(G C A g r_{1}\right)+c_{2} M S\left(G C A g r_{2}\right)+c_{3} M S(S C A)+c_{4} Q M R\right]^{2}}{\frac{\left[c_{1} M S\left(G C A g r_{1}\right)\right]^{2}}{p+1}+\frac{\left[c_{2} M S\left(G C A g r_{2}\right)\right]^{2}}{q+1}+\frac{\left[c_{3} M S(S C A)\right]^{2}}{p q}+\frac{\left[c_{4} Q M R\right]^{2}}{N(u-1)}} \quad v_{4}=\frac{\left[d_{1} M S(S C A)+\left(1-d_{1}\right) Q M R\right]^{2}}{\frac{\left[d_{1} M S(S C A)\right]^{2}}{p q}+\frac{\left[\left(1-d_{1}\right) Q M R\right]^{2}}{N(u-1)}}$

$v_{5}=\frac{\left[d_{2} M S(S C A)+\left(1-d_{2}\right) Q M R\right]^{2}}{\left[d_{2} M S(S C A)\right]^{2}}$

$\underline{\left[d_{2} M S(S C A)\right]^{2}}+\underline{\left[\left(1-d_{2}\right) Q M R\right]^{2}}$

Where: $\quad \mathrm{b}_{1}=\frac{q-1}{q+1} ; \mathrm{b}_{2}=\frac{q(p+1)}{q+1} ; \mathrm{b}_{3}=\frac{p-1}{q+1} ; \quad \mathrm{b}_{4}=\frac{p(q+1)}{q+1} ; \mathrm{c}_{1}=\frac{p(p+q+2)}{N(2+q)} ; \quad \mathrm{c}_{2}=\frac{q(p+q+2)}{N(2+p)}$;

$c_{3}=\frac{2 p q\left(3 p^{3} q+3 q^{3}+3 p^{3}+3 q^{3}+6 p^{2} q^{2}+p^{2} q^{3}+p^{3} q^{2}+4 q+4 p+8 q+8 p^{2}+8 q^{2}+\mathbb{0} p^{2} q+\mathbb{1} g^{2}\right)}{\left.N(2+q) 2+p) 2 p^{2} q+2 q^{2}+3 p^{2}+3 q^{2}+\mathbb{0} p+1 p+1 q+2\right)}$;

$d_{1}=\frac{2(q+1 \chi 2+p \ell p+q+2)}{2 p^{2} q+2 q^{2}+3 p^{2}+3 q^{2}+\mathbb{0} q+1 p+1 q+\mathcal{L}} \quad d_{2}=\frac{2(p+1) 2+q \ell p+q+2)}{2 p^{2} q+2 q^{2}+3 p^{2}+3 q^{2}+\mathbb{0} p+1 p+1 q+\mathcal{L}}$

$\hat{\sigma}_{s}^{2}=\frac{(2+q)(2+p)(p+q+2)}{u\left(2 p^{2} q+2 p q^{2}+3 p^{2}+3 q^{2}+10 p q+11 p+11 q+12\right)}[M S(S C A)-M S R]$

$\hat{\sigma}_{r}^{2}=\frac{1}{2 u}[M S(C I T)-M S R] ; \quad \hat{\sigma}_{d 1}^{2}=\frac{1}{2 u q}\left[M S\left(M A T g r_{1}\right)-M S(C I T)\right] ; \hat{\sigma}_{d 2}^{2}=\frac{1}{2 u p}\left[M S\left(M A T g r_{2}\right)-M S(C I T)\right]$

\section{RESULTS}

The observed variation, in both fixed and random effect models, was partitioned into GCAgr1, GCAgr2, SCA, REC, MATgr1, MATgr2, and CIT effects. The results of these parameters were similar, mainly because the analysis of variance is very similar in both models. In the fixed-effect model, GCAgr1 and SCA were significant, and in the random effect model, only SCA was statistically significant (Table 4).

In the fixed model, the treatment effect was statistically significant for grain yield, suggesting mean differences among some of the $20 \mathrm{~F}_{1}$ 's, 20 reciprocals and 9 parents (Table 4). As the GCAgr1 and SCA effects were statistically significant 
Table 4. Variance and diallel analysis for grain yield considering fixed and random effects

\begin{tabular}{|c|c|c|c|c|c|}
\hline \multicolumn{6}{|l|}{ Fixed effects } \\
\hline Source of Variation & df & Sum of Squares & Mean Square & $\mathbf{F}$ & $P$-value \\
\hline Treatments & 48 & 238306781 & 4964725 & 3.563 & 0.000000 \\
\hline Block & 2 & 21608144 & 10804072 & 7.753 & 0.000756 \\
\hline Residual & 96 & 41388973 & 431135 & & \\
\hline Total & 146 & 393696024 & & & \\
\hline Group & 1 & 3995786 & 3995786 & 2.867 & 0.0936 \\
\hline SCA & 20 & 162530585 & 8126529 & 5.832 & 0.0000 \\
\hline MATgr $_{1}$ & 4 & 1379999 & 345000 & $0.277^{* *}$ & 0.9375 \\
\hline MATgr $_{2}$ & 3 & 4307305 & 1435768 & $0.943^{* *}$ & 0.4530 \\
\hline CIT & 12 & 8057475 & 671456 & 0.482 & 0.9209 \\
\hline \multicolumn{6}{|c|}{ Estimates of least square } \\
\hline \multicolumn{6}{|c|}{$\hat{\phi}_{g r}=357875.39 ; \hat{\emptyset}_{g 1}=279602.55 ; \hat{\emptyset}_{g 2}=47659.89 ; \hat{\emptyset}_{s}=1090154.12 ; \hat{\emptyset}_{d 1}=0^{*} ; \hat{\emptyset}_{d 2}=0^{*} \hat{\emptyset}_{r}=0^{*}$} \\
\hline Group & 1 & 3995785.71 & 3995785.71 & $0.7714^{* * *}$ & 0.3886 \\
\hline $\mathrm{GCAgr}_{1}$ & 4 & 46605184.68 & 11651296.17 & $1.4706^{* * *}$ & 0.2480 \\
\hline $\mathrm{GCAgr}_{2}$ & 3 & 10761959.97 & 3587319.99 & $0.4424^{* * *}$ & 0.7253 \\
\hline SCA & 20 & 162530584.70 & 8126529.24 & 5.8315 & 0.0000 \\
\hline MATgr $_{1}$ & 4 & 1379999.37 & 344999.85 & 0.5138 & 0.7271 \\
\hline MATgr $_{2}$ & 3 & 4307304.57 & 1435768.20 & 2.1383 & 0.1486 \\
\hline CIT & 12 & 8057475.27 & 671456.28 & 0.4818 & 0.9209 \\
\hline Residual & 96 & 133781099.00 & 1393553.10 & & \\
\hline
\end{tabular}

Estimates of components of variance

$\hat{\sigma}_{g r}^{2}=0^{*} ; \hat{\sigma}_{g 1}^{2}=103563.41 ; \hat{\sigma}_{g 2}^{2}=0 * \hat{\sigma}_{s}^{2}=2238672.16 ; \hat{\sigma}_{d 1}^{2}=0^{*} ; \hat{\sigma}_{d 2}^{2}=25477.06 ; \hat{\sigma}_{r}^{2}=0^{*}$

"This value should be considered zero when negative. ${ }^{* *}$ The $\mathrm{df}$ for linear combination of least squares in the numerator of F-test on fixed effects was estimated with the Satterthwaite approximation for maternal effect in the groups 1 and 2 , with values of $v_{1}=5.535$ and $v_{2}=4.679$, respectively. ${ }^{* * *}$ The df for linear combination of least squares in the denominator of F-test for random effects were estimated by the Satterthwaite approximation for Group with $v_{3}=23.620, \mathrm{GCAgr}_{1}$ and $\mathrm{GCAgr}_{2}$ with $v_{4}=20.214$ and $\mathrm{v}_{5}=20.017$, respectively.

for GY, this indicates the importance of genes whit both additive and non-additive effects controlling this trait. However,

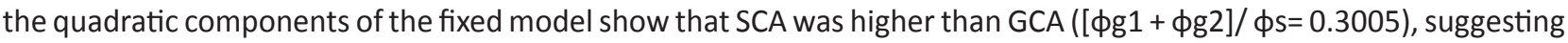
the predominance of non-additive gene effects on grain yield (Table 4).

The group effects (contrast between Group $1 \mathrm{v} / \mathrm{s}$ Group 2) and GCAgr2 showed non-statistical significance (Table 4). This result indicates that, for GY, the additive genetic effects are similar between Group 1 and Group 2.

In the random model, the variances between groups (P-value $=0.3886)$ and GCA in both groups (GCAgr1 and GCAgr2) were not statistically significant (P-value $=0.2480$ and 0.7253 , respectively). In contrast, the variance for SCA was significant ( $P$-value $<0.1$ ), indicating that $\mathrm{GY}$ was influenced by non-additive effects. In both fixed and random effect models, maternal effects for both groups were not statistically significant (MATgr1 P-value $=0.9375 ;$ MATgr2 P-value = 0.4530 and CIT P-value $=0.9209$ ), suggesting that GY was not controlled by reciprocal effects (Table 4).

The best parents for GY were the hybrids AG8080, Flash and Dekalb 350. Based on SCA effects, the best double and multiple-cross hybrids were the crosses CD3121-1 (gr1) x 30F80 (gr2) (SCAS26 = 1284.96) and Dekalb $350(\operatorname{gr} 1) \times$ CD3121-2 (gr2) (SCAS59 = 1135.12) (Table 5). Although these combinations have no practical commercial applications, they can be improved by interpopulational breeding strategies.

\section{DISCUSSION}

In diallel analysis based on a fixed effect model, the comparison of the results is restricted to the least square means 
of the set of parents used in the diallel analysis, whereas the results obtained through the random effect model the inference can be made from the population that these parents are derived, based on the components of variance (Baker 1978). In breeding programs, it is very usual to consider the treatments (e.g., genotypes) as random

Table 5. Estimates of genetic parameters for fixed model

\begin{tabular}{|c|c|c|c|}
\hline \multicolumn{2}{|c|}{ Group1 } & \multicolumn{2}{|c|}{ Group2 } \\
\hline Parameters & Estimates & Parameters & Estimates \\
\hline $\mathrm{gr}_{1}$ & -377.27 & $\mathrm{gr}_{2}$ & 392.99 \\
\hline$S E\left[\hat{g} r_{1}-\hat{g} r_{2}\right]$ & 454.88 & - & - \\
\hline g1 & -616.69 & g6 & $285 \cdot 89$ \\
\hline g2 & -598.53 & g7 & $-73 \cdot 47$ \\
\hline g3 & 611.25 & g8 & $164 \cdot 48$ \\
\hline g4 & 300.84 & g9 & $-376 \cdot 90$ \\
\hline g5 & 303.15 & - & - \\
\hline$S E\left[\hat{g} r_{i}-\hat{g} r_{k}\right]$ & 278.24 & $S E\left[\hat{g} r_{j}-\hat{g} r_{k}\right]$ & $257 \cdot 60$ \\
\hline S11 & 1745.39 & S66 & $169 \cdot 34$ \\
\hline S22 & 2010.99 & S77 & $1864 \cdot 21$ \\
\hline S33 & 151.65 & S88 & $1742 \cdot 24$ \\
\hline S44 & 1708.79 & S99 & $1024 \cdot 58$ \\
\hline S55 & -816.45 & - & - \\
\hline$S E\left[\hat{s}_{i 0}-\hat{s}_{k 0}\right]$ & 786.99 & - & - \\
\hline d1 & 31.55 & d6 & -47.79 \\
\hline d2 & 30.81 & d7 & 223.65 \\
\hline d3 & 153.81 & d8 & -214.64 \\
\hline d4 & -75.48 & d9 & -259.78 \\
\hline d5 & 232.49 & & \\
\hline$S E\left[\hat{d}_{i}-\hat{d}_{k}\right]$ & 340.78 & $S E\left[\hat{d}_{j}-\hat{d}_{k^{\prime}}\right]$ & 357.41 \\
\hline S16 & -521.35 & r16 & -266.46 \\
\hline S17 & -693.09 & r17 & 142.21 \\
\hline S18 & -637.44 & r18 & -157.89 \\
\hline S19 & 106.49 & r19 & -16.40 \\
\hline S26 & 1284.96 & r26 & -537.26 \\
\hline S27 & -65.24 & $r 27$ & -131.99 \\
\hline S28 & 119.95 & $\mathrm{r} 28$ & 159.77 \\
\hline S29 & -3350.67 & $r 29$ & 210.94 \\
\hline S36 & -404.68 & r36 & 87.24 \\
\hline S37 & -260.35 & r37 & -255.71 \\
\hline S38 & -86.03 & r38 & 227.43 \\
\hline S39 & 599.41 & r39 & -357.51 \\
\hline S46 & -592.35 & r46 & -49.57 \\
\hline S47 & -651.56 & r47 & 276.75 \\
\hline S48 & -949.96 & r48 & -207.24 \\
\hline S49 & 485.08 & r49 & -318.49 \\
\hline S56 & 64.08 & r56 & 392.86 \\
\hline S57 & -193.97 & r57 & -404.44 \\
\hline S58 & -188.77 & r58 & -395.25 \\
\hline S59 & 1135.12 & r59 & 108.27 \\
\hline$S E\left[\hat{s}_{i j}-\hat{s}_{k j}\right]$ & 622.17 & $S E\left[\hat{r}_{i j}-\hat{r}_{k j}\right]$ & 762.00 \\
\hline$S E\left[\hat{s}_{i j}-\hat{s}_{i k}\right]$ & 630.99 & $S E\left[\hat{r}_{i j}-\hat{r}_{i k^{\prime}}\right]$ & 746.61 \\
\hline$S E\left[\hat{s}_{i j}-\hat{s}_{k k}\right]$ & 585.54 & $S E\left[\hat{r}_{i j}-\hat{r}_{k k}\right]$ & 1180.49 \\
\hline
\end{tabular}

SE: Standard Error. effect, mainly due to the interest in genetic components of variance, although considering them as fixed effect allows the comparison between the genotypes used in the crosses.

The reciprocal and maternal effects are essential for the selection of inbred lines as female or male parents. In addition, reciprocal effects have been reported for a number of quantitative traits in maize (Fan et al. 2008, Yao et al. 2013, Fan et al. 2014). Commonly, plant breeders use diallel methods without estimates of MAT and REC effects (e.g., Griffing's Methods 2 and 4), which causes lack of information and may result in unexploited superior crosses (Yao et al. 2013). Thus, we proposed a new partial diallel model adapted to analyze reciprocal effects allowing the computation of reciprocal as well as maternal and cytoplasmic effects.

The results of this study suggest that GY was not controlled by reciprocal effects in either group (MATgr1 and MATgr2), in agreement with reports of Zare et al. (2011), who pointed out that reciprocal effects were not significant for GY. In contrast, other authors concluded that the interaction of cytoplasmic and nuclear genes affects significantly hybrid performance for GY and other important agronomic traits (Zhang et al. 2016). According to Yao et al. (2013), for example, reciprocal effects have a major impact on the determination of hybrid yield. More specifically, the results of Fan et al. (2014) showed that considering reciprocal crosses in a diallel model greatly impacted GY and estimates of GCA and SCA effects. In addition, Zhang et al. (2016) mentioned that these results indicate the need for a new hypothesis that can fully explain heterosis, taking the cytoplasmic genes and their interaction with nuclear genes into account.

As proposed by Fan et al. (2014), considering the impact of reciprocal crosses on GY and SCA estimation, the possible result would have a great impact on maize heterotic group classification. Another study recently reported how MAT influenced GCA effects and how REC affected SCA effects in Griffing's Method 1 and 3 (Mahgoub 2011). The current proposed model should be relevant to analyze a partial diallel mating design, using key genetic statistics that allow the computation of REC as well as maternal (MAT) and cytoplasmic effects (CIT). None of the above studies reported the impact of reciprocal crosses or REC on a partial diallel mating design. 


\section{NM Barata et al.}

The proposed model generates additional information about partitioning GCA and SCA effects to estimate maternal and reciprocal effects in a partial diallel mating design, and would help to identify each parent used as male or female parent and provide precise information about the nature of the interaction between the best parent combinations.

\section{REFERENCES}

Baker (1978) Issues in diallel analysis. Crop Science 18: 533-558.

Cockerham CC and Weir BS (1977) Quadratic analyses of reciprocal crosses. Biometrics 33: 187-203.

EMBRAPA (2006) Nutrição e adubação do milho. Embrapa Milho e Sorgo, Sete Lagoas, 10p.

Fan XM, Chen HM, Tan J, Xu CX, Zhang YM, Huang YX and Kang MS (2008) A new maize heterotic pattern between temperate and tropical germplasms. Agronomy Journal 100: 917-923.

Fan XM, Zhang YD, Yao WH, Bi YQ, Liu L, Chen HM and Kang MS (2014) Reciprocal diallel crosses impact combining ability, variance estimation, and heterotic group classification. Crop Science 54: 89-97.

Ferreira EA, Guimarães PS, Silva RM and Paterniani MEAG (2008) Combining ability of tropical and temperate maize inbred lines germplasm and heterosis of single-crosses hybrids. Revista Biociências 1: 32-40.

Gardner CO and Eberhart SA (1966) Analysis and interpretation of the variety cross diallel and related populations. Biometrics 22: 439-452.

Gaylor DW and Hopper FN (1969) Estimating the degrees of freedom for linear combinations of mean squares by Satterthwaite's formula. Technometrics 11: 691-706.

Geraldi IO and Miranda Filho JB (1988) Adapted models for the analysis of combining ability of varieties in partial diallel crosses. Brazilian Journal of Genetics 11: 419-430.

Griffing B (1956) Concept of general and specific combining ability in relation to diallel crossing systems. Australian Journal of Biological Sciences 9: 463-493.

Hayman BI (1954a) The analysis of variance of diallel crosses. Biometrics 10: $235-244$.

Hayman BI (1954b) The theory and analysis of diallel crosses. Genetics
39: 789-809.

Magari R, Kang MS and Zhang YD (1996) Sample size for evaluation of grain dry-down rate in corn. Maydica 41: 19-24.

Mahgoub GMA (2011) Partitioning of general and specific combining ability effects for estimating maternal and reciprocal effects. Journal of Agricultural Science 3: 213-221.

Miranda Filho JB and Geraldi IO (1984) An adapted model for the analysis diallel crosses. Brazilian Journal of Genetics 7: 667-688.

Sahai $\mathrm{H}$ and Ojeda MM (2004) Analysis of variance from random models: theory, methods, applications, and data analysis. Birkhauser, Boston, 408p.

Satterthwaite FE (1946) An approximate distribution of estimates of variance components. Biometrics Bulletin 2: 110-114.

Yao WH, Zhang YD, Kang MS, Chen HM, Liu L, Yu LJ and Fan XM (2013) Diallel analysis models: A comparison of certain genetic statistics. Crop Science 53: 1481-1490.

Zare M, Choukan R, Heravan EM, Bihamta MR and Ordookhani K (2011) Gene action of some agronomic traits corn (Zea mays L.), using diallel cross analysis. African Journal of Agricultural Research 6: 693-703.

Zhang Y and Kang MS (1997) DIALLEL-SAS: A SAS program for Griffing's diallel analyses. Agronomy Journal 89: 176-182.

Zhang Y, Kang MS and Lamkey KR (2005) DIALLEL-SAS05: A comprehensive program for Griffing's and Gardner-Eberhart analyses. Agronomy Journal 97: 1097-1106.

Zhang Y, Kang MS and Magari R (1997) Genetics of resistance to kernel infection by Aspergillus flavus in maize. Plant Breeding 116: 146-152.

Zhang YD, Fan X, Yao W, Piepho HP and Kang MS (2016) Diallel analysis of four maize traits and a modified heterosis hypothesis. Crop Science 56: 1115-1126.

(cc) EY This is an Open Access article distributed under the terms of the Creative Commons Attribution License, which permits unrestricted use, distribution, and reproduction in any medium, provided the original work is properly cited. 